\title{
O HABITUS PROFESSORAL E A EDUCAÇÃO ESPECIAL: PERCEPÇÃO DOS PROFESSORES DE CLASSE COMUM E SALA DE RECURSOS MULTIFUNCIONAL
}

\author{
EL HABITUS DE PROFESSORES Y LA EDUCACIÓN ESPECIAL: \\ PERCEPCIÓN DE LOS PROFESORES DE AULA COMÚN Y AULA DE \\ RECURSOS MULTIFUNCIONAL
}

\section{THE HABITUS PROFESSORIAL AND SPECIAL EDUCATION: PERCEPTIONS OF COMMON CLASS TEACHERS AND RESOURCE ROOM MULTIFUNCIONAL}

\author{
Norberto Kuhn JUNIOR ${ }^{1}$ \\ Helena Venites SARDAGNA ${ }^{2}$ \\ Valdir PEDDE ${ }^{3}$ \\ Fatima Liliane Oliveski ROTH ${ }^{4}$
}

RESUMO: Este artigo analisa a educação inclusiva a partir do Atendimento Educacional Especializado (AEE) em Sala de Recursos Multifuncional (SRM) na rede municipal de Ensino de Novo Hamburgo/RS. Contou com a participação de 99 professores de classe comum que atuavam na docência de alunos com deficiência, transtorno global do desenvolvimento e altas habilidades/superdotação e 30 professoras de SRM no ano de 2013. Os dados apontaram que as professoras de SRM demonstraram possuir menores dificuldades em trabalhar com os alunos da Educação Especial do que os professores de classe comum. Por meio da identificação do habitus dos professores de classe comum, compreendeu-se que as dificuldades indicadas por eles decorrem da fragilidade em sua formação pedagógica para trabalhar com alunos da Educação Especial. Trata-se de um habitus não inclusivo, o qual se constituiu desde a interiorização de modelos de ensino pautado pela homogeneização dos sujeitos (todos são iguais) em detrimento da constituição de um novo habitus, estruturante de um modelo de ensino que reconheça as diversidades para sua inclusão.

PALAVRAS-CHAVE: Inclusão escolar. Sala de recursos multifuncional. Habitus professoral.

\footnotetext{
${ }^{1}$ Programa de Pós-graduação em Diversidade Cultural de Inclusão Social da Universidade FEEVALE, na linha de pesquisa Inclusão Social e Políticas Públicas. Ainda como pesquisador é vinculado ao Projeto OBEDUC - Diversidade, acesso e permanência: práticas sociais e pedagógicas na Educação Básica do Observatório da Educação - OBEDUC/MEC-CAPES. Email: nkjunior@ feevale.br

2 Professora da graduação e pós-graduação da Universidade Estadual do Rio Grande do Sul (Uergs); coordenadora do Curso de Pedagogia - Licenciatura da Uergs - Unidade de Osório/RS; líder do Grupo de Pesquisa Educação e Processos Inclusivos (GPEPI) na Uergs; integrante do Grupo de Estudo e Pesquisa em Inclusão (GEPI) na Unisinos. Email: sardagn@ terra.com.br

3 Doutor em Antropologia pela Universidade Federal do Rio Grande do Sul. Professor no Programa de Pós-graduação em Diversidade Cultural de Inclusão Social da Universidade Feevale. É pesquisador no Projeto OBEDUC - Diversidade, acesso e permanência: práticas sociais e pedagógicas na Educação Básica do Observatório da Educação - OBEDUC/MEC-CAPES e líder do Grupo de Pesquisa Metropolização e Desenvolvimento Regional da FEEVALE/CNPq. Email: valpe @ feevale.br

${ }^{4}$ Pesquisadora no Projeto OBEDUC - Diversidade, acesso e permanência: práticas sociais e pedagógicas na Educação Básica do Observatório da Educação. Email: fatima.o.roth@gmail.com
} 
RESUMEN: Este artículo analiza la educación inclusiva desde la Atención Educacional Especializada (AEE) en Aula de Recursos Multifuncional (ARM) en la red de municipios de Enseñanza de Novo Hamburgo/RS. Hubo la participación de 99 profesores de aula común que actuaban en la docencia de alumnos con discapacidad, transtorno global del desarrollo y altas habilidades/superdotados y 30 profesoras de ARM en el año de 2013. Los datos señalaron que las profesoras de ARM demostraron poseer menores dificultades en trabajar con los alumnos de la Educación Especial que los profesores de aula común. Por medio de la identificación del habitus de los profesores de aula común, se pudo comprender que las dificultades indicadas por ellos resultan de la fragilidad en su formación pedagógica para trabajar con alumnos de la Educación Especial. Se trata de un habitus no-inclusivo, el cual se constituye desde la interiorización de modelos de enseñanza enmarcado por la homogeneización de los sujetos (todos son iguales) en detrimento de la constitución de un nuevo habitus, estructurante de un modelo de enseñanza que reconozca las diversidades para su inclusión.

PALABRAS CLAVE: Inclusión escolar. Aula de recursos multifuncional. Habitus de profesores.

ABSTRACT: This article analyzes the Inclusive Education from the Specialized Educational Service (SES) in Multifunctional Resources Classes (MRC) in the Municipal Teaching web in Novo Hamburgo/RS. It counted with the participation of 99 teachers in the regular classroom who worked as teachers of students with disabilities, pervasive developmental disorders, high ability/gifted and 30 MRC teachers in 2013. The data showed that the MRC teachers shown to have minor difficulties in working with students from the Special Education than the teachers of regular class. Through the identification of the teachers' habitus of regular class, it was understood that the difficulties indicated by them derive from the fragility in their pedagogical training to work with students of Special Education. It is about a non-inclusive habitus, which is constituted from the internalization of teaching models based on the subject homogenization (all are equal) over the constitution of a new habitus, structural of a teaching model that recognizes the diversity for inclusion.

KEYWORDS: Educational inclusion. Multifunctional resources classes. Teacherly habitus.

\section{Introdução}

O movimento para a educação inclusiva teve início no Brasil na década de noventa, sendo fortalecido com a Declaração de Salamanca ${ }^{5}$ em 1994, desde então, muito se tem discutido sobre essa questão. Duas décadas se passaram e ainda se percebe a necessidade de discutir o tema, pois a escola, assim como a sociedade, continua em

${ }^{5}$ Conferência, organizada pelo Governo da Espanha em cooperação com a UNESCO, realizada em Salamanca, de 7 a 10 de junho de 1994. Seu princípio orientador consistiu em afirmar que as escolas devem ajustar-se a todas as crianças, independentemente das suas condições físicas, sociais, linguísticas ou outras. (BRASIL, 1994). 
processo de consolidação do objetivo de tornar-se um lugar para todos. De acordo com Beyer (2006), a configuração do quadro da Educação Especial, há alguns anos, indicava os alunos com deficiência para as escolas especiais ${ }^{6}$ e os alunos sem deficiência para as escolas regulares. No entanto, na atualidade, a Educação Especial encontra-se em profundas mudanças e políticas públicas foram criadas com o objetivo de construir espaços escolares inclusivos e, dessa forma, retirar as pessoas com deficiência das escolas especiais. Uma das políticas públicas criadas foi o Programa Educação Inclusiva: Direito à Diversidade, lançado no ano de 2003 pelo Ministério da Educação por meio da Secretaria de Educação Especial (SEESP) ${ }^{7}$. Essa política tem, entre seus objetivos, apoiar a implantação de Salas de Recursos Multifuncionais (SRMs) para favorecer o processo de inclusão educacional na rede pública de ensino (BRASIL, 2005).

O foco de análise nesse artigo $^{8}$ está direcionado às dificuldades apontadas pelos professores sobre a atuação com os alunos com deficiência, transtornos globais do desenvolvimento e altas habilidades/superdotação ${ }^{9}$. Como pergunta norteadora dessa reflexão temos: "qual a percepção dos professores de sala de aula comum e das professoras de sala de recursos multifuncional sobre as dificuldades vivenciadas no seu trabalho com os alunos da educação especial?". Para responder a essa questão entendemos ser importante abordá-la em sua relação com a formação inicial e continuada dos referidos professores.

Apresentamos uma explanação inicial sobre as salas de recursos multifuncionais na rede municipal de ensino de Novo Hamburgo. Na sequência, valendo-se dos resultados obtidos na pesquisa com relação à formação inicial e continuada dos professores de classe comum e sala de recursos multifuncional dessa rede de ensino, contextualizamos a formação de professores em tempos de educação inclusiva, de modo

${ }^{6}$ Entende-se por escolas especiais os espaços que por muito tempo foram os únicos que atendiam pessoas com deficiências (BEYER, 2006).

${ }^{7}$ A SEESP foi extinta, no ano de 2012, por meio do Decreto $n^{\circ} 7.690 / 12$, e suas atribuições passaram para a Diretoria de Políticas de Educação Especial (DPEE), vinculada à Secretaria de Educação Continuada, Alfabetização, Diversidade e Inclusão (SECADI) (BRASIL, 2012).

8 Este artigo resulta de parte dos dados da pesquisa "A Educação Inclusiva no município de Novo Hamburgo: A Sala de Recursos Multifuncional em Foco", desenvolvida no âmbito do Projeto OBEDUC - Diversidade, acesso e permanência: práticas sociais e pedagógicas na Educação Básica do Observatório da Educação - OBEDUC/MEC-CAPES. Os resultados integrais resultaram em Dissertação de Mestrado, com o mesmo título, apresentado ao Programa de Pós-Graduação em Diversidade Cultural e Inclusão Social da Universidade Feevale/RS, em Fevereiro de 2014.

${ }^{9}$ Alunos com deficiência, transtorno global do desenvolvimento e altas habilidades/superdotação é a nomenclatura atualizada para designar o público da Educação Especial e a mesma decorre da Política Nacional de Educação Especial na Perspectiva da Educação Inclusiva. Essa nomenclatura encontra-se atualizada na LDBN 9.394/96 pela Lei n ${ }^{\circ} 12.796$, de 4 de abril de 2013. 
a compor entendimento sobre a importância da formação pedagógica, que contemple discussões sobre a educação de alunos com deficiência, transtorno global do desenvolvimento e altas habilidades/superdotação, visando a capacitação dos professores para atuar na docência desses alunos.

Posteriormente apresentamos os principais resultados de nossa investigação com foco na percepção dos professores (de sala de aula comum e das salas de recursos multifuncionais) sobre as dificuldades vivenciadas com alunos da educação especial. Conduzimos essa reflexão considerando dois aspectos dessa realidade: descrevemos o marco referencial das ações desses professores (com base na Nota Técnica SEESP-GAB n¹9/2010) e, através da noção de habitus de Pierre Bourdieu, buscamos pistas para compreender os fundamentos das dificuldades vivenciadas nas práticas desses profissionais.

\section{Sala de recursos multifuncional na rede municipal de ensino de Novo Hamburgo}

Como dito anteriormente, a Secretaria de Educação Especial/MEC desenvolveu o Programa Educação Inclusiva: Direito à Diversidade, que apresenta como um dos seus objetivos a implantação de Salas de Recursos Multifuncionais, destinadas ao atendimento educacional especializado, com vistas a apoiar o processo de inclusão educacional dos alunos com necessidades educacionais especiais na rede pública de ensino (BRASIL, 2005).

O documento Sala de Recursos Multifuncionais: Espaço para o Atendimento Educacional Especializado, elaborado pela Secretaria de Educação Especial/MEC em 2006, apresenta a definição de Sala de Recursos Multifuncional como sendo:

Espaços da escola onde se realiza o atendimento educacional especializado para alunos com necessidades educacionais especiais, por meio do desenvolvimento de estratégias de aprendizagem, centradas em um novo fazer pedagógico que favoreça a construção de conhecimentos pelos alunos, subsidiando-os para que desenvolvam o currículo e participem da vida escolar. (BRASIL, 2006, p. 13).

O Atendimento Educacional Especializado citado no documento e reiterado pela Resolução do CNE/CEB 4/2009, em seu Art. $2^{\circ}$, refere que o AEE tem como função

Complementar ou suplementar a formação do aluno por meio da disponibilização de serviços, recursos de acessibilidade e estratégias que eliminem as barreiras para sua plena participação na sociedade e desenvolvimento de sua aprendizagem. (BRASIL, 2009, p.1-2). 
A Sala de Recursos Multifuncional é, portanto, um "espaço organizado com materiais didáticos e pedagógicos, equipamentos e profissionais com formação para o atendimento das necessidades educacionais especiais. " (BRASIL, 2006, p. 14).

Até o ano de 2013, foram disponibilizadas pelo MEC, por meio da Secretaria de Educação Continuada, Alfabetização, Diversidade e Inclusão (SECADI), 5.820 Salas de Recursos Multifuncionais para o Estado do Rio Grande do Sul (BRASIL. SECADI, 2013). A rede municipal de ensino de Novo Hamburgo iniciou o recebimento das Salas de Recursos Multifuncionais no ano de 2010 e possui atualmente um total de 44 salas.

Os dados da pesquisa revelaram que a maioria das professoras (12) que responderam o questionário ingressou nas SRMs no ano de 2010 e que no ano da coleta dos dados (2013) houve o ingresso de cinco professoras para atuarem nas SRMs. A maioria das professoras de SRM das escolas alcançadas pela pesquisa informou que atendem somente os alunos da própria escola onde está situada a sala.

\section{Formação de professores em tempos de educação inclusiva}

A partir da Declaração de Salamanca (BRASIL, 1994), a educação inclusiva passou a ser tema central nas discussões educacionais; com isso, a formação de professores ocupou espaço importante nas discussões em torno da questão.

No Brasil, a LDBEN no 9394/96 ressalta a formação do professor como imprescindível para o sucesso da educação e refere, no inciso III do Art. 59, que a formação de professores para o atendimento de alunos com deficiência, transtornos globais do desenvolvimento e altas habilidades/superdotação ${ }^{10}$ poderá ser realizada por meio de cursos em nível médio ou superior.

Nos últimos anos, a Educação Especial apresentou mudanças quanto às diretrizes legais no que se refere à educação inclusiva. Destaca-se a Resolução do CNE/CEB n²/2001, que institui as Diretrizes Nacionais para a Educação Especial na Educação Básica.

Com relação à formação do professor, esta Resolução afirma que os professores que trabalham com alunos que apresentam necessidades educacionais especiais podem seguir dois modelos distintos: os capacitados e os especializados. O Art. 18, inciso IV, apresenta a definição de professor capacitado:

${ }^{10}$ Alteração na redação da LDBEN no 9394/96dada pela Lei no 12.796 de 2013 
$\S 1^{\circ}$ São considerados professores capacitados para atuar em classes comuns com alunos que apresentam necessidades educacionais especiais aqueles que comprovem que, em sua formação, de nível médio ou superior, foram incluídos conteúdos sobre Educação Especial adequados ao desenvolvimento de competências. (BRASIL, 2001, p.7-8).

Observa-se que, em nível médio e superior, a formação de professores deve ocorrer por meio de oferecimento de disciplinas que contemplem as discussões sobre o processo educacional de alunos com deficiência e que capacitem os mesmos para reconhecer as especificidades dos alunos, flexibilizar a sua prática pedagógica e avaliar o processo de ensino e aprendizagem.

Os professores especializados, segundo o mesmo Artigo, são os responsáveis pela organização das ações pedagógicas a serem desenvolvidas pelos professores capacitados. Conforme o Art. $18 \S 3^{\circ}$, devem ter sua formação em nível superior ou em nível de especialização. Os professores especializados são definidos como:

$\S 2^{\circ}$ professores especializados em Educação Especial são aqueles que desenvolveram competências para identificar as necessidades educacionais especiais para definir, implementar, liderar e apoiar a implementação de estratégias de flexibilização, adaptação curricular, procedimentos didáticos pedagógicos e práticas alternativas, adequados ao atendimento das mesmas, bem como trabalhar em equipe, assistindo o professor da classe comum nas práticas que são necessárias para promover a inclusão dos alunos com necessidades educacionais especiais. (BRASIL, 2001).

Redig (2010) destaca que essa Resolução abre a possibilidade, novamente, de transferência da responsabilidade dos cursos de nível superior, visto que surge a opção para a formação dos professores na área de Educação Especial nos cursos de pósgraduação.

Com efeito, a Resolução CNE/CP n ${ }^{\circ} 1$ de 2006 instituiu a reforma no curso de Pedagogia, extinguindo as habilitações, incluindo a de Educação Especial, que até então era o modelo mais tradicional de formação nessa área no País. A formação desses professores especialistas passa a ser indicada para que ocorra em nível de pós-graduação (BRASIL, 2006a).

Dando continuidade às reflexões sobre a formação de professores para a Educação Inclusiva, no ano de 2008, foi criada a Política Nacional de Educação Especial na Perspectiva da Educação Inclusiva (PNEE-PEI). A PNEE-PEI apresenta entre seus objetivos a "formação de professores para o atendimento educacional 
especializado e demais profissionais da educação para a inclusão.” (BRASIL, 2008). Segundo essa política, para atuar na Educação Especial como professor do AEE, o professor deve:

ter como base da sua formação, inicial e continuada, conhecimentos gerais para o exercício da docência e conhecimentos específicos da área [ ] deve contemplar conhecimentos de gestão de sistema educacional inclusivo, tendo em vista o desenvolvimento de projetos em parceria com outras áreas, visando à acessibilidade arquitetônica, aos atendimentos de saúde, à promoção de ações de assistência social, trabalho e justiça. (BRASIL, 2008b).

A PNEE-PEI refere também que os professores do atendimento educacional especializado devem ter:

conhecimentos específicos no ensino da Língua Brasileira de Sinais, da Língua Portuguesa na modalidade escrita como segunda língua, do sistema Braille, do soroban, da orientação e mobilidade, das atividades de vida autônoma, da comunicação alternativa, do desenvolvimento dos processos mentais superiores, dos programas de enriquecimento curricular, da adequação e produção de materiais didáticos e pedagógicos, da utilização de recursos ópticos e não ópticos, da tecnologia assistiva e outros. (BRASIL, 2008b).

Sobre as atribuições do professor do AEE e sua formação inicial e continuada constantes nos documentos normativos, em relação à Educação Especial na perspectiva da Educação Inclusiva, podemos destacar as posições de Mendes (2011), que considera bastante complexa a formação desse professor, pois deve envolver habilidades e conhecimentos para trabalhar com todos os tipos de alunos com necessidades educacionais especiais. Refere que a citada política- não faz referência às funções docentes propriamente ditas e não deixa claro o papel do professor especializado, a não ser pela especificação de que ele não deve fazer o que o professor do ensino comum faz e que o professor especializado deverá ser algum professor do ensino comum que acumulará uma formação especializada. Ou seja, uma formação continuada, não considerando a possibilidade de formação especializada desde o processo de formação inicial.

Já a posição de Baptista (2011, p.64), seguindo o Art. 12 da PNEE-PEI, destaca que o professor deve ter formação inicial que o habilite para o exercício da docência e a formação específica para a Educação Especial. O autor faz o questionamento de que “essa formação específica será bastante diversificada, considerando-se as potencialidades de formação e os quadros existentes nos diferentes estados brasileiros”. 
No entanto, o autor salienta que há uma valorização do trabalho compartilhado com outros profissionais, principalmente com o docente do ensino comum, e que as atribuições que implicam "conexões/articulações entre o docente especializado e o professor do ensino comum abrem espaço para a discussão curricular necessária nos processos inclusivos." (BAPTISTA, 2011, p.64-65).

Percebe-se que a posição dos autores anteriormente citados se assemelha quanto à complexidade exigida na formação do professor do AEE. No entanto, há o reconhecimento por parte de um dos autores da valorização do trabalho compartilhado entre o professor especializado (professor de SRM) e o professor do ensino comum.

Destacamos que no ensino colaborativo, ocorre uma parceria entre o professor da educação regular e o professor da Educação Especial (SRM). Mendes (2006) refere que nessa parceria- os dois profissionais trabalham juntos e "dividem a responsabilidade de planejar, instruir e avaliar um grupo heterogêneo de estudantes, assim compartilhando objetivos, expectativas e frustrações. " (MENDES, 2006 apud MENDES, 2011).

Com base nas reflexões realizadas anteriormente sobre a formação inicial e continuada dos professores de classe comum (considerados pela Resolução do CNE/CEB n²/2001 como professores capacitados) e das professoras de SRM (consideradas pela Resolução do CNE/CEB n²/2001 como professoras especializadas), verificamos o perfil de formação dos mesmos: percebe-se que os professores de classe comum, com relação à formação inicial, em sua maioria possuem magistério e licenciatura concluída na área de ciências humanas. Destaca-se ainda um percentual considerável de professores que não possuem formação continuada. Igualmente, as professoras de SRM indicaram possuir magistério e licenciatura concluída na área de ciências humanas como formação inicial. Destaca-se que todas as professoras de SRM participantes da pesquisa indicaram possuir curso de formação continuada, como se vê no quadro abaixo: 
Quadro 1 - Perfil de formação inicial e continuada dos professores pesquisados (SRM e classe comum).

\begin{tabular}{|l|c|c|}
\hline \multicolumn{1}{|c|}{ Formação } & $\begin{array}{c}\text { Prof. de } \\
\text { SRM }\end{array}$ & $\begin{array}{c}\text { Prof. de } \\
\text { classe } \\
\text { comum }\end{array}$ \\
\hline Formação continuada: pós-graduação/Especialização - concluído & $73 \%$ & $42 \%$ \\
\hline Formação continuada: pós-graduação/Especialização - cursando & $12 \%$ & $14 \%$ \\
\hline Formação continuada: pós-graduação/Mestrado concluído & - & $6 \%$ \\
\hline Formação continuada: pós-graduação/Mestrado cursando & - & - \\
\hline Sem formação continuada & - & $20 \%$ \\
\hline
\end{tabular}

Fonte: autores

Buscamos ainda identificar o nível de satisfação com os subsídios adquiridos nos cursos de formação inicial e formação continuada para atuação com os alunos da Educação Especial. Temos que a maioria das professoras de SRM está satisfeita com os cursos de formação de ensino médio, superior e nos cursos de formação continuada. Já os níveis de satisfação entre os professores de classe comum, sobre os subsídios adquiridos nos cursos de formação de ensino médio, superior e nos cursos de formação continuada para a atuação com os alunos da Educação Especial, indicam percepção negativa dos mesmos.

A identificação do perfil dos professores com relação à formação inicial e continuada e a satisfação com os subsídios adquiridos nas mesmas, nos ajudam a entender as dificuldades expressas pelos professores de classe comum para trabalhar com os alunos da Educação Especial. Esses dados nos dizem que a negatividade indicada na formação pedagógica desses professores não os constitui como professores capacitados, como sugere a Resolução CNE/CEB n²/2001, e a fragilidade dessa formação está diretamente relacionada com as dificuldades indicadas pelos professores de classe comum, as quais são apresentadas a seguir.

\section{Dificuldades para a atuação com os alunos com deficiência, transtornos globais do desenvolvimento (TGD) e altas habilidades/superdotação}

Com relação às dificuldades apontadas na pesquisa pelos dois segmentos de professores para a atuação com os alunos do AEE, as professoras de SRM apresentaram positividade nas respostas (plano do AEE, número de alunos participantes da SRM, uso 
de Tecnologia Assistiva (TA), produção de materiais didáticos e pedagógicos acessíveis) relacionadas a esse item.

As maiores dificuldades apontadas pelos professores de classe comum dizem respeito ao profissional de apoio à inclusão e a TA. Os professores de classe comum apresentaram como item de muita dificuldade a inexistência do profissional de apoio à inclusão em sala de aula, destacando esses profissionais como indispensáveis em qualquer circunstância. Salientaram igualmente a falta desse profissional em sala de aula como sendo a principal dificuldade para trabalhar com os alunos da Educação Especial.

Quanto aos profissionais de apoio para os alunos com deficiência, TGD e altas habilidades/superdotação, item apontado pela maioria dos professores de classe comum como sendo de grande dificuldade quando inexistente, a Nota Técnica SEESP-GAB No19/2010 refere que:

[...] Os profissionais de apoio às atividades de locomoção, higiene, alimentação, prestam auxílio individualizado aos estudantes que não realizam essas atividades com independência. Esse apoio ocorre conforme as especificidades apresentadas pelo estudante, relacionadas à sua condição de funcionalidade e não à condição de deficiência. [...] Não é atribuição do profissional de apoio desenvolver atividades educacionais diferenciadas ao aluno público alvo da Educação Especial, nem responsabilizar-se pelo ensino desse aluno. (BRASIL, 2010, p. 2).

A rede municipal de ensino de Novo Hamburgo apresenta uma diferenciação em relação às orientações da Nota Técnica no 19/2010. É orientação dessa rede de ensino que os profissionais de apoio à inclusão prestem auxílio ao professor de classe comum no desenvolvimento de atividades com os alunos do AEE e com a turma em geral. Isso significa que esse apoio disponibilizado não se restringe somente às atividades de locomoção, higiene e alimentação para o aluno do AEE; para além dessas atribuições, esse profissional atua auxiliando o professor de classe no que for necessário com os alunos do AEE e com o restante da turma. A rede municipal de ensino de Novo Hamburgo orienta que o professor de classe e o profissional de apoio à inclusão devem articular-se no desenvolvimento e na aplicabilidade de atividades para os alunos do AEE, estabelecendo, dessa forma, um trabalho colaborativo. Assim, o profissional de apoio à inclusão, nessa rede de ensino, atua pedagogicamente com os alunos do AEE, ainda que os documentos legais, como a Política Nacional de Educação Especial na 
Perspectiva da Educação Inclusiva de 2008 e a Nota Técnica SEESP-GAB nº19 de 2010, não façam referência à atuação pedagógica desse profissional.

Analisando-se os dados apontados pela maioria dos professores de classe comum, percebe-se que estes atribuíram um significado de extrema importância à existência, em sala de aula, do profissional de apoio à inclusão para o desenvolvimento do trabalho com os alunos do AEE. Os dados indicaram que a inexistência e/ou despreparo desse profissional é percebida como a principal dificuldade no trabalho com os alunos da Educação Especial. Chama atenção a resposta dos professores sobre esse quesito quando apontam que concordam plenamente que, independentemente da deficiêncialtranstorno do aluno do AEE, o profissional de apoio à inclusão é indispensável para o auxílio no desenvolvimento do trabalho em sala de aula com esses alunos. Ressalta-se que a expressão independentemente da deficiência/transtorno abre espaço para reflexões de que nem toda deficiência ou transtorno necessita de apoio diferenciado. No entanto, os professores de classe não atentaram para essa questão quando responderam a pesquisa.

Percebe-se, assim, pela concordância com essa afirmativa, que a maioria dos professores de classe comum entende que é diretamente proporcional a equação: aluno da Educação Especial versus profissional de apoio; em outras palavras, a existência do profissional de apoio à inclusão é condição para a existência dos alunos da Educação Especial em sala de aula, independentemente da deficiência ou transtorno. Esse entendimento, segundo Mazzotta (1998), mostra a correspondência necessária entre Educação Especial para alunos percebidos como especiais e educação comum para alunos percebidos como comuns (MAZZOTTA, 1998, apud STELMACHUK, MAZZOTTA, 2012). Concordando com a maioria dos professores de classe comum sobre o profissional de apoio, o dizer de uma professora de área ${ }^{11}$ sintetiza essa ideia:

Para mim, é indispensável, independentemente do aluno. A M., quando não tem alguém que fique com ela, ela fica copiando o que tem no quadro, eu fico angustiada porque os alunos pedem muito a minha presença. Eu não sento nunca, estou sempre circulando, ajudando a todos. (Professora de Área).

Apesar de a maioria dos professores de classe comum ter indicado a falta do profissional de apoio à inclusão, independentemente da deficiência do aluno do AEE,

${ }^{11}$ No presente estudo, o professor de área é aquele que atua em uma área específica dos anos finais. $\mathrm{O}$ professor de currículo refere-se ao professor que atua na educação infantil e nos anos iniciais do ensino fundamental. 
como item de grande dificuldade para o trabalho com os alunos da Educação Especial, acreditamos ser importante apresentar ao leitor as considerações feitas por algumas professoras de classe comum com relação à qualificação desses profissionais de apoio.

Eu acredito que cada caso é um caso, que o professor de apoio é um plus, é uma coisa a mais que vem enriquecer o teu trabalho, que vem realmente te dar esse apoio necessário, mas um professor de apoio inexperiente, sem toda a bagagem necessária até para ser professor como tal, isso às vezes dificulta o trabalho em sala de aula [...]. Então, seria muito mais válido que a gente tivesse um professor bem qualificado, não uma estagiária de magistério, que infelizmente não tem subsídio, ela está aprendendo, o trabalho dela é ficar ali e aprender junto contigo. A gente precisa de alguém qualificado que saiba intervir, que saiba ajudar, que saiba pensar na hora, isso não deu certo, isso é o meu dia a dia, não deu certo na hora, eu tenho que inventar. (Professoras de Currículo).

Percebe-se, com os dizeres dessas professoras, que elas possuem o entendimento da necessidade do trabalho colaborativo entre o professor de sala de aula e o profissional de apoio à inclusão, contrariando o que diz a legislação sobre esses profissionais, que refere que estes devem atuar somente nas atividades de locomoção, higiene e alimentação dos alunos da Educação Especial.

Identificamos no decorrer da análise dos dados da pesquisa; que houve respostas contraditórias entre professores de classe comum e professoras de SRM, caracterizando assim, pontos de tensão na percepção das dificuldades para se trabalhar com os alunos da Educação Especial. Apresentamos a seguir os pontos de tensão identificados.

\section{$1^{\circ}$ Ponto de tensão - tecnologia assistiva em sala de aula}

As professoras de SRM indicaram no questionário que possuem pouca dificuldade em ampliar o uso da TA da SRM para a sala de aula comum. Contrariando as respostas das professoras de SRM, a maioria dos professores de classe comum informou que não há o uso da TA em sala de aula e referiram também que há um número significativo de professores que não possuem conhecimento sobre TA.

O comentário de uma professora que participou da entrevista pode nos auxiliar no entendimento dessa tensão. Quando questionada sobre o que teria a dizer sobre o uso da TA em sala de aula, ela informou que:

Tecnologia, sim, mas o termo assistiva, não. [...] Eu acho que a gente não conhece todos os materiais disponíveis, porque, de repente, se a 
gente conhecesse, a gente poderia pensar "ah, isso pode ser interessante". [...] A gente teve também um problema de computadores... Várias vezes, eu tive alunos que necessitavam do computador para o registro. Os computadores nunca funcionavam. Então, eles eram instalados, vinha o instalador para colocar tomada, o computador ficava ali o ano inteiro no lugar, mas não funcionava, era um problema de rede elétrica. E, às vezes, um notebook para a escola inteira não é o bastante para atender toda a demanda. (Professora de currículo).

Outra professora apresenta seu entendimento quando questionada sobre o uso da Tecnologia Assistiva em sala de aula:

Eu não tenho nenhum recurso tecnológico na sala, não é utilizado. $\mathrm{O}$ contato que eles têm é semanal, no laboratório de informática, e a gente tem a professora específica na parte da manhã. Então, o que a gente procura fazer é o mesmo que em sala de aula, adaptar as atividades que vão ser feitas para os alunos, adaptar de acordo com as possibilidades deles quando há a necessidade. (Professora de currículo).

Faz-se necessário retomarmos o conceito de Tecnologia Assistiva:

Tecnologia Assistiva é uma área do conhecimento, de característica interdisciplinar, que engloba produtos, recursos, metodologias, estratégias, práticas e serviços que objetivam promover a funcionalidade, relacionada à atividade e participação de pessoas com deficiência, incapacidades ou mobilidade reduzida, visando sua autonomia, independência, qualidade de vida e inclusão social. (BRASIL.CORDE, 2009, p. 9).

Entende-se que Tecnologia Assistiva diz respeito a todo e qualquer recurso utilizado para aumentar, manter ou melhorar as capacidades funcionais das pessoas com deficiência. Como exemplos, podemos citar: brinquedos adaptados, bengala, recursos para mobilidade manual, como tesoura especial, engrossador de lápis, prancha imantada, talheres, equipamentos de comunicação alternativa, computadores, softwares, etc.

As professoras, nos depoimentos anteriores, demonstram não possuir conhecimento do que seja a Tecnologia Assistiva, pois as respostas remetem apenas ao uso dos computadores (laboratório de informática e notebook). Pode-se pensar, com isso, que o fato de a grande maioria dos professores de classe comum ter informado na pesquisa que não há o uso da TA em sala de aula decorra do desconhecimento do que seja exatamente a TA. Desse modo, desconhecendo a abrangência da TA, os professores não identificam o seu uso em sala de aula. 


\section{$2^{\circ}$ Ponto de tensão - terceirização da aprendizagem}

Um segundo ponto de tensão que identificamos foi com relação à percepção da transferência da responsabilidade da aprendizagem do aluno do AEE do professor de classe comum para o profissional de apoio à inclusão.

Apesar de apontarem a necessidade do profissional de apoio à inclusão em sala de aula em qualquer circunstância, os professores de classe indicaram entender que não devem terceirizar para esses profissionais a aprendizagem dos alunos do AEE, ou seja, evidenciaram que os profissionais de apoio não são os responsáveis pela aprendizagem dos alunos da Educação Especial.

Contrapondo a afirmativa anterior dos professores de classe comum, as professoras de SRM acreditam que o profissional de apoio à inclusão conhece em maior medida o nível de aprendizagem dos alunos do AEE do que o professor titular. Essa percepção das professoras de SRM no que diz respeito à relação dos profissionais de apoio à inclusão com os professores de classe comum significa que não há o trabalho colaborativo entre esses dois tipos de profissional e que o profissional de apoio à inclusão muitas vezes é o responsável pela aprendizagem do aluno do AEE.

Destacamos que, nos estágios de interação referidos por Gately e Gately (2001), o primeiro estágio é aquele em que a comunicação entre os professores envolvidos (aqui representados pelo professor de classe comum e profissional de apoio) é superficial e há a necessidade de compreenderem o processo do trabalho colaborativo para poderem avançar para o próximo estágio. (GATELY; GATELY, 2001 apud ASSIS; MENDES; ALMEIDA, 2011). Sendo assim, professores de classe comum e profissional de apoio à inclusão encontram-se nesse estágio de relação. Outro aspecto dessa tensão diz respeito à formação dos professores de classe comum. Os professores de classe comum sabem que é de sua atribuição promover a aprendizagem de todos os alunos, com deficiência ou não. Em função disso, informaram na pesquisa que discordam de que o profissional de apoio à inclusão seja o responsável pela aprendizagem do aluno do AEE. No entanto, também indicaram que não possuem conhecimentos suficientes para atuar com esses alunos, podendo justificar, assim, a percepção das professoras de SRM quanto à transferência da responsabilidade da aprendizagem do aluno do AEE para o profissional de apoio à inclusão. 


\section{$3^{\circ}$ Ponto de tensão - planejamento antecipado}

O terceiro ponto de tensão identificado na pesquisa refere-se ao planejamento antecipado das atividades para os alunos do AEE por parte do professor de classe comum.

O planejamento antecipado é realizado pelo professor de classe comum para o aluno do AEE, com o objetivo de solicitar auxílio das professoras de SRM e para que estas possam, em tempo hábil, propor estratégias de atuação, adaptar material ou tomar outra providência necessária à plena participação do aluno em sala de aula. Importante destacar que o planejamento inicial parte do professor de classe, mas que, com a interlocução com a SRM, passa a ser coletivo, desencadeando o trabalho colaborativo com este profissional. Com relação ao planejamento antecipado, houve divergência nas respostas dos professores, pois as professoras de SRM indicaram que há muita dificuldade dos professores de classe em realizar o planejamento antecipado a fim de que elas possam auxiliar na sua aplicabilidade, enquanto os professores de classe indicaram que possuem pouca dificuldade em realizá-lo.

O depoimento de duas professoras de SRM quanto ao planejamento antecipado realizado pelo professor de classe comum para os alunos do AEE nos auxilia a entender esse ponto de tensão.

Eu acho que ele [professor de classe comum] não vê ainda [o professor de SRM] como alguém que pode ajudar no planejamento. Eu acho que tem um caminho ali ainda para se andar [...]. A maioria dos professores não faz o planejamento antecipado para que eu possa auxiliar a tempo, daí, fica difícil [...]. O ideal é quando a professora já traz sugestões, às vezes, elas não trazem, daí, tu tens que buscar. Eu acho fantástica essa troca, só que nem sempre ela é bem entendida. (PROFESSORAS DE SRM).

Analisando-se os depoimentos das professoras de SRM explicitadas acima, percebe-se que, no quesito planejamento antecipado, a articulação/comunicação entre Educação Especial e classe comum não ocorre. No entanto, pensamos que, para além da articulação que esse quesito exige, está implícito o empoderamento do professor de classe comum quando este não realiza o planejamento antecipado visando a solicitar auxílio da professora de SRM e, com isso, desencadear o trabalho colaborativo.

O depoimento de uma professora de SRM explicita nosso pensamento com relação a esse item: 
O que eu percebo que é um dado meu, da escola, a equipe também sabe que no currículo algumas professoras se sentem donas do seu aluno, porque permanecem com ele. Então, a minha entrada é como uma interferência, com um olhar de que elas não estão dando conta [...]. Aí, mexe com essa questão, assim, se tu estás me dizendo isso, é porque eu não estou vendo, e daí é como uma interferência [...]. Em alguns momentos, eu percebo isso, que tu fazes uma entrada e que tu tens uma resistência nesta questão do planejamento [...]. Não conseguem ter essa visão integrada, de que poderia estar articulando, mas é um caminho. (Professora de SRM).

A partir dos relatos anteriores, observa-se que esse ponto de tensão identificado na pesquisa envolve articulação e trabalho colaborativo, o qual é essencial para o êxito da inclusão escolar. Com relação a esse quesito, os professores necessitam deixar de exercer o papel de único responsável pela aprendizagem dos alunos, para então vivenciar o compartilhamento dos saberes, das responsabilidades, das metas, das avaliações e das rotinas de sala de aula, assim efetivando o trabalho colaborativo entre Educação Especial e classe comum.

Finalizamos aqui a análise descritiva dos resultados revelados na pesquisa, em torno dos obstáculos ao desenvolvimento da educação inclusiva apontados pelos professores dessa rede de ensino. Em seguida, procuraremos destacar as dificuldades inerentes a uma boa parcela de professores em função de terem sido aprimorados para o desenvolvimento da docência antes de um contexto de uma educação inclusiva.

\section{O habitus professoral e os obstáculos ao desenvolvimento da educação inclusiva}

Nesta parte do trabalho, buscamos, com a identificação do habitus dos professores que participaram da pesquisa (explicitado nas respostas do questionário e entrevista), compreender as principais dificuldades apontadas por eles (existência do profissional de apoio à inclusão, planejamento para os alunos do AEE e uso da Tecnologia Assistiva em sala de aula) no trabalho desenvolvido com os alunos do Atendimento Educacional Especializado.

Retomando a definição de habitus, Bourdieu o compreende como:

[...] um sistema de disposições duráveis e transponíveis que, integrando todas as experiências passadas, funciona a cada momento como uma matriz de percepções, de apreciações e de ações - e torna possível a realização de tarefas infinitamente diferenciadas, graças às 
transferências analógicas de esquemas. (BOURDIEU, 1983, apud BAIRROS, 2011, p.14).

O habitus, então, é uma disposição que persiste e que vai se integrando às experiências de vida. Não é imutável, portanto, sofre modificações ao longo da trajetória do indivíduo. Pode-se dizer desse modo, que as experiências vivenciadas pelos professores em sua formação inicial e continuada formaram uma matriz de percepções, as quais são utilizadas em suas práticas pedagógicas atuais e futuras.

Cabe lembrar que centramos o olhar na noção de habitus secundário, expresso por Bourdieu, ou seja, aquele proveniente da educação escolar.

\section{Habitus e modelos educacionais na formação dos professores - sistema classificatório e não inclusivo}

Os professores de classe comum, em sua maioria, indicaram que possuem como formação inicial no nível médio o magistério, e o curso superior de licenciatura na área humana. A época de formação indicada pelos professores para os cursos de formação em nível médio situa-se, em sua maior parte, entre as décadas de 80 e 90; para os cursos de formação superior, situa-se na década de 2000.

Importante lembrar que foi a partir de meados da década de 1990 que começaram no Brasil as discussões em torno do novo modelo educacional denominado inclusão escolar, o qual se opunha ao movimento de integração escolar vivenciado até então. Chamamos atenção para o fato de que a transição de um sistema educacional para outro, no caso, do integracionista para o inclusivo, não ocorre de forma linear, sendo que, com frequência, há a simultaneidade de ambos nos espaços escolares.

O modelo educacional vigente à época do início da formação inicial dos referidos professores era o modelo integracionista, no qual o aluno da Educação Especial, ao ingressar no ensino comum, precisava adequar-se à sistemática da escola, sendo que a sua integração ocorria em níveis graduados, conforme suas possibilidades. Esse modelo educacional transferia para o aluno a responsabilidade de adequar-se e adaptar-se às exigências da escola comum, ou seja, a possibilidade de sucesso no ambiente escolar era tarefa do aluno, cabendo-lhe adaptar-se à escola.

Portanto, no início de seus cursos de formação, os professores de classe comum participantes desta pesquisa vivenciaram esse modelo, o qual não exigia do professor, nem da escola, mudanças ou adaptações em sua prática pedagógica para atender os 
alunos da Educação Especial. Sobre a prática pedagógica, Bourdieu refere que a igualdade formal que pauta a prática pedagógica "serve como máscara e justificação para a indiferença no que diz respeito às desigualdades reais diante do ensino e da cultura transmitida, ou melhor dizendo, exigida." (BOURDIEU, 1999, p.53). Dessa forma, a matriz de percepções e apreciações adquiridas pelos referidos professores, a qual pautará suas ações futuras, decorreu desse modelo de sistema escolar.

A continuidade da formação inicial dos professores participantes da pesquisa ocorreu igualmente na década de 90 e 2000, quando já se vivenciava o modelo educacional denominado inclusão. Portanto, a formação inicial dos referidos professores ocorreu entre o modelo educacional integracionista, descrito acima, e o modelo inclusivo vigente. No entanto, cabe lembrar o que foi descrito acima, a fragilidade do Ensino Superior ligado às licenciaturas e mesmo à pedagogia no que se refere à capacitação dos professores para uma educação inclusiva. Retomando o pensamento de Bourdieu sobre habitus, este diz que, da mesma forma que o habitus adquirido por meio da inculcação familiar é condição primordial para a estruturação das experiências escolares, o "habitus transformado pela ação escolar constitui o princípio de estruturação de todas as experiências ulteriores, incluindo desde a recepção das mensagens produzidas pela indústria cultural até as experiências profissionais." (BOURDIEU, 2004, apud PIES, 2011, p. 45). Assim, vivenciando a transição dos modelos educacionais do integracionista para o inclusivo, o professor, em seu processo de formação, que fundamentalmente ancorava-se no habitus constituído em um modelo de ensino integrativo, é chamado, sem a preparação adequada, a integrar-se em uma matriz educativa e de visão de mundo inclusiva. Obviamente que esta situação tenderia a, de maneira geral, gerar dificuldades para os docentes.

Com relação às dificuldades apontadas pelos professores de classe comum para trabalhar com os alunos do AEE, destaca-se a dificuldade relativa aos profissionais de apoio à inclusão. Os professores indicaram ter muita dificuldade quando esse profissional não existe em sala de aula, apontando-o como indispensável, independentemente da deficiência do aluno. Destacaram igualmente a falta desse profissional em sala de aula como sendo a principal dificuldade para trabalhar com os alunos da Educação Especial. Percebe-se que os referidos professores necessitam de outro profissional para auxiliá-los em sua prática pedagógica com esse aluno que os provoca diariamente com seu saber/não saber diferente, que os convoca para mudanças e os desafia naquilo que até então estava estruturado e sabido. 
Podemos pensar que, quando os professores desta pesquisa colocam a necessidade da existência do apoio à inclusão em sala de aula, independentemente da deficiência do aluno, eles nos dizem que não se sentem seguros para trabalhar com esses alunos, pois a imagem que carregam é a de um ensino que potencializa a homogeneização e não a diferença. Portanto, a partir das respostas dos professores de classe comum identificamos que esses professores possuem um habitus estruturado no ensino integrativo, o qual representa a escola classificatória, com tempos e espaços marcados, que busca a homogeneização de todos, que ensina da mesma forma todos os alunos e que entende que há escolas comuns para alunos sem deficiência e escolas especiais para alunos com deficiência. O habitus, dessa maneira, dispõe a separação entre Educação Especial e comum.

Se, como diz Bourdieu (1998), o habitus é um princípio gerador e unificador que traduz as características de uma classe, de estilos de vida, de escolhas de bens e de práticas, então, o habitus dos professores desta pesquisa se traduz no cotidiano escolar, na sala de aula e na prática pedagógica com os alunos da Educação Especial. Ou seja, os professores ensinam como aprenderam a ensinar (todos da mesma maneira) e como vivenciaram essa aprendizagem.

Com relação à dificuldade apontada no planejamento antecipado, a fim de solicitar auxílio da SRM, destacamos anteriormente o empoderamento do professor de classe comum. Supomos que, quando os professores de classe não buscam realizar o planejamento em conjunto com a professora de SRM, isso ocorre em função de que eles não se sentem confortáveis em admitir, mostrar, deixar transparecer suas dificuldades em elaborar atividades significativas para os alunos do AEE. Desse modo, não desenvolvendo o trabalho colaborativo, passam a ser os únicos responsáveis pela aprendizagem dos alunos, evitando sentir-se questionados em seu saber e podendo gozar da liberdade para ensinar da maneira que aprenderam a ensinar. Sendo assim, novamente o professor reproduz o que internalizou, o que aprendeu e vivenciou. Como diz Bourdieu, o habitus é produto de condicionantes que fazem com que reproduzamos as condições sociais de nossa própria reprodução e que podem ser o princípio gerador da ação do professor (SILVA, 2008; ORTIZ, 2003).

Com relação à Tecnologia Assistiva, identificamos que os professores de classe comum não a reconhecem, como descrevemos anteriormente. Relembramos que os referidos professores indicaram uma predominância de percepção negativa para os subsídios adquirida nos cursos de formação inicial e continuada para trabalhar com os 
alunos da Educação Especial. Entendemos que a trajetória de formação dos referidos professores e, consequentemente, o seu habitus, não contemplaram conhecimentos sobre a TA. Valendo-nos novamente de Bourdieu, este diz que, à medida que as condições sociais e históricas são alteradas, o habitus também se modifica e vai incorporando outros esquemas de percepção e ação, que irão contribuir para a conservação ou a transformação de suas estruturas (BOURDIEU, 1998; SILVA, 2008). Sendo assim, o habitus desses professores não incorporou outros esquemas de percepção e ação, conservando a estrutura já adquirida, o que explica, por exemplo, o não reconhecimento do uso da Tecnologia Assistiva em sala de aula.

\section{Considerações finais}

O movimento para a educação inclusiva ocorre no Brasil há duas décadas, e, para auxiliar esse processo, políticas públicas foram criadas com o objetivo de construir espaços educacionais inclusivos. Destacamos a política pública que instrumentalizou as escolas com a implantação das Salas de Recursos Multifuncionais, ou seja, o Programa Educação Inclusiva: Direito à Diversidade.

Com relação às dificuldades para a atuação com os alunos com deficiência, transtornos globais do desenvolvimento e altas habilidades/superdotação, os dados coletados apontaram positividade nas respostas das professoras de SRM e negatividade nas respostas dos professores de classe comum nos seguintes itens: profissional de apoio à inclusão, Tecnologia Assistiva e planejamento antecipado.

Considerando-se as professoras de SRM, a positividade expressa pelas referidas professoras, quanto às possíveis dificuldades para trabalhar com os alunos da Educação Especial, se articulam com a positividade indicada pelas mesmas nos cursos de formação inicial e continuada.

Por conseguinte, identificamos que a negatividade expressa nas respostas dos professores de classe comum indicando dificuldades para trabalhar com os alunos do AEE está diretamente relacionada à negatividade indicada na formação pedagógica desses professores.

Igualmente percebemos que as dificuldades expressas pelos professores de classe comum, especialmente a relativa à necessidade do profissional de apoio à inclusão como condição para a existência do aluno da Educação Especial em sala de 
aula, dizem-nos que o professor ainda pensa a Educação Especial separada da educação comum, mesmo que ambas compartilhem o mesmo espaço educativo.

Assim, nossa intenção foi demarcar o habitus dos professores de classe comum, participantes da pesquisa, para então compreender a gênese das dificuldades desses professores em trabalhar com os alunos do AEE.

A partir da identificação do habitus dos professores de classe comum, entendemos que as dificuldades apontadas com relação aos alunos do AEE se justificam pelo habitus não inclusivo incorporado por eles no decorrer de sua trajetória de formação profissional. Em outras palavras, os professores desta pesquisa, com relação às dificuldades expostas, não romperam com o habitus constituído (fundado no modelo de ensino pautado pela homogeneização de todos). A constituição de um novo habitus, estruturante de um modelo de ensino que reconhece as diferenças, ainda carece de disposições objetivas (meios e recursos) para orientar e organizar as condutas desses profissionais.

Destacamos ainda que o habitus dos professores é igualmente dado pelo sistema classificatório da sociedade onde a mesma encontra-se inserida e que esse sistema não está presente somente nos professores de classe comum e sim, na direção da escola, nas concepções da Secretaria de Educação e em alguma medida pode estar presente nas professoras da SRM.

\section{REFERÊNCIAS}

ASSIS, C.P; MENDES, E. G; ALMEIDA, M. A. Ensino colaborativo: um relato de experiência sobre o desenvolvimento de parceria colaborativa. Revista de Educação. Vol. 6, $\mathrm{n}^{\circ} 11,2011$.

BAIRROS, M. S. O habitus e a atuação docente: estudo sobre as conexões entre habitus e trabalho docente. (Mestrado em Educação) Universidade Federal do Rio Grande do Sul, Programa de Pós-Graduação em Educação, Porto Alegre, 2011.

BAPTISTA, C. R. Ação pedagógica e Educação Especial: a sala de recursos como prioridade na oferta de serviços especializados. Rev. Bras. Ed. Esp., Marília, v.17, p.59-76, Maio-Ago, 2011.

BEYER, H. O. Inclusão e avaliação na escola: de alunos com necessidades educacionais especiais. $2^{\mathrm{a}}$. ed. Porto Alegre: Mediação, 2006.

BOURDIEU, P. O poder Simbólico. 2a . ed. Rio de Janeiro: Bertrand Brasil, 1998. 
BOURDIEU, P. Escritos de Educação. 2a ${ }^{a}$ ed. Petrópolis: Editora Vozes, 1999.

BRASIL. Declaração de Salamanca e linha de ação sobre necessidades educativas especiais. Brasília: UNESCO, 1994.

Lei n. 9.394, de 20 de dezembro de 1996. Lei de Diretrizes e Bases da Educação Nacional, 1996.

Resolução no 2 de 11 de setembro de 2001. Institui as Diretrizes Nacionais da Educação Especial na Educação Básica, Ministério da Educação/ SEESP, Brasília, 2001.

Programa educação inclusiva: Direito à diversidade. Documento Orientador. Brasília, MEC, 2005.

Sala de Recursos Multifuncional: Espaço para Atendimento Educacional Especializado. MEC/SEESP, 2006.

Resolução CNE/CP No 1, DE 15 de maio de 2006. Institui Diretrizes Curriculares Nacionais para o Curso de Graduação em Pedagogia, licenciatura. Conselho Nacional de Educação/Conselho Pleno, 2006a.

Política Nacional de Educação Especial na Perspectiva da Educação Inclusiva. Secretaria de Educação Especial - MEC/SEESP, 2008.

Resolução No. 4, de 2 de outubro de 2009. Institui as Diretrizes Operacionais para o Atendimento Educacional Especializado na Educação Básica, na modalidade Educação Especial. Conselho Nacional de Educação/Câmara de Educação Básica, 2009.

Nota Técnica SEESP/GAB/N $\mathbf{N}^{\mathbf{0}}$ 19/2010. Profissionais de apoio para alunos com deficiência e transtornos globais do desenvolvimento matriculados nas escolas comuns da rede pública de ensino, SECADI, 2010c.

Decreto n⿳ 7.690, de 02 de março de 2012. Aprova a Estrutura Regimental e o Quadro Demonstrativo dos Cargos em Comissão e das Funções Gratificadas do Ministério da Educação. 2012. Diário Oficial da União, Brasília, 6 mar. 2012. Disponível em <http://www.planalto.gov.br/ccivil_03/_Ato20112014/2012/Decreto/D7690.htm>. Acesso em: 06 jun. 2012.

. Lei $\mathbf{n}^{\mathbf{0}}$ 12.796, de 4 de abril de 2013. Altera a Lei $\mathrm{n}^{0}$ 9.394, de 20 de dezembro de 1996, que estabelece as Diretrizes e Bases da Educação Nacional, para dispor sobre a formação dos profissionais da educação e dar outras providências.

BRASIL.CORDE. Subsecretaria Nacional de Promoção dos Direitos da Pessoa com Deficiência. Comitê de Ajudas Técnicas. Brasília: CORDE. Disponível em: $<$ http://www.pessoacomdeficiencia.gov.br/app/sites/default/files/publicacoes/livrotecnologia-assistiva.pdf>. Acesso em: 02 jun. 2012.

BRASIL.SECADI. Relação dos municípios polos e respectivas abrangências. SECADI, 2013. Disponível em <http://portal.mec.gov.br〉. Acesso em: 01 set. 2013.

JESUS, D. M; ALVES, E. P. Serviços educacionais especializados: desafios à formação inicial e continuada. In: BAPTISTA, C. R; CAIADO, K. R. M; JESUS, D. M 
(Orgs.) Professores e Educação Especial: formação em foco. Porto Alegre: vol. 2, Mediação, 2011. p. 17-28.

MENDES, E. G. A formação do professor e a política nacional de Educação Especial. In: BAPTISTA, C. R; CAIADO, K. R. M; JESUS, D. M (Orgs.) Professores e Educação Especial: formação em foco. Porto Alegre: vol. 2, Mediação, 2011. p. 131146.

ORTIZ, R. A sociologia de Pierre Bourdieu. Renato Ortiz (Org). São Paulo: Olho d'Água, 2003.

PIES, N. G. Capital cultural e educação em Bourdieu. (Dissertação de Mestrado). Universidade de Passo Fundo, Faculdade de Educação. Passo Fundo, 2011.

REDIG, A. G. Ressignificando a Educação Especial no contexto da Educação Inclusiva: a visão de professores especialistas. (Mestrado em Educação). Universidade do Estado do Rio de Janeiro, Centro de Educação e Humanidades, Rio de Janeiro, 2010.

ROTH. F.L.O. A Educação Inclusiva no município de Novo Hamburgo: A Sala de Recursos Multifuncional em Foco. (Dissertação de Mestrado). Universidade Feevale, Novo Hamburgo, 2014.

SILVA, M. A. S. A utilização do conceito de habitu sem Pierre Bourdieu para a compreensão da formação docente. Revista Extra-Classe, nº1, v.2, Agosto 2008.

STELMACHUK, A.C.L; MAZZOTTA, M.J.S. Atuação de profissionais da educação na inclusão escolar do aluno com deficiência intelectual. Rev. Educ. Espec., Santa Maria, v. 25, n. 43, p. 185-202, maio/ago. 2012. Disponível em:

<http://www.ufsm.br/revistaeducacaoespecial>. Acesso em: 20 set 2013.

\section{Como referenciar este artigo}

KUHN JUNIOR, Norberto et al. O habitus professoral e a educação especial: percepção dos professores de classe comum e sala de recursos multifuncional. Revista IberoAmericana de Estudos em Educação, Araraquara/SP, v. 11, n. 3, p.1198-1220, 2016. Disponível em: 〈https://dx.doi.org/10.21723/riaee.v11.n3.7297〉. E-ISSN: 1982-5587.

Submetido em: 02/10/2014

Aprovação Final em: 26/07/2016 